\title{
Lançando luzes sobre a gestão de operações do setor eletroeletrônico brasileiro
}

\author{
Ana Beatriz Lopes de Sousa Jabbour \\ Universidade Estadual Paulista \\ Charbel José Chiappetta Jabbour \\ Universidade Estadual Paulista
}

\begin{abstract}
Este artigo tem como objetivo apresentar e discutir a gestão de operações no setor eletroeletrônico brasileiro. O setor eletroeletrônico é dos mais relevantes do Brasil, correspondendo a $4 \%$ do Produto Interno Bruto (PIB). Grande parte da literatura disponível centra-se na discussão de políticas para fortalecimento do setor sem, no entanto, discutir sua gestão de operações, ainda pouco conhecida. Para suprir essa carência da literatura, realizou-se uma pesquisa quantitativa, por meio de survey com empresas da Associação Brasileira da Indústria Elétrica e Eletrônica (Abinee). Os dados coletados foram complementados com dados secundários, traçando um panorama sobre o setor no Brasil. Os resultados indicam a necessidade de as empresas montadoras de produtos eletroeletrônicos investirem mais no uso de tecnologia da informação para ampliar a integração de processos, planejar e desenvolver produtos integrando os clientes, e com os fornecedores ampliar a adoção de práticas de gestão da cadeia de suprimentos. A originalidade deste artigo consiste em lançar luzes à gestão de operações de um setor economicamente importante gerando insights a estudiosos, praticantes e formuladores de políticas voltadas ao setor eletroeletrônico nacional.
\end{abstract}

Palavras-chave: gestão de operações; setor eletroeletrônico; Brasil.

Shedding light on the operations management in Brazilian electro-electronics sector This article aims to present and discuss the operations management in the Brazilian electronics sector. The electronics sector is one of the most important in Brazil, accounting for $4 \%$ of Gross Domestic Product (GDP). Much of the available literature focuses on the discussion of policies to strengthen the sector, without, however, to discuss its operations management, yet little known. To fill this gap in the literature, a quantitative research has been conducted, through a survey with companies of the Brazilian Association of Electrical and Electronics Industry (Abinee). The collected data were supplemented with secondary data, drawing a big picture about the sector in Brazil. The results indicate the need for companies to invest more in using information technology to expand the integration of processes, planning and developing products integrating with customers and suppliers, increases adoption of

Artigo recebido em 13 fev. 2011 e aceito em 15 ago. 2011.

RAP - Rio de Janeiro 46(3):817-40, maio/jun. 2012 
management practices in the supply chain. The originality of this paper is to shed light on the operations management of an economically relevant sector generating insights for scholars, practitioners and policymakers focused on Brazilian electronics sector.

KEY WORDS: operations management; electronics sector; Brazil.

\section{Introdução}

A gestão de operações é responsável pelo alcance da eficiência e eficácia do processo de transformação (Prentis, 1987), a partir de um conjunto de políticas e práticas definidas e implementadas pela empresa com o objetivo de atender ao mercado (Fleury, 1999).

Atualmente, a gestão de operações tem de lidar com a crescente complexidade dos sistemas de produção, juntamente com mudanças profundas na estrutura da indústria e na diferenciação dos papéis a serem desempenhados pelas diferentes empresas dentro de cadeias de suprimentos. Isso é causado por fatores tais como as tecnologias da informação (TI) e a globalização (Fleury e Fleury, 2007). Conforme Prentis (1987), mudanças que estão ocorrendo no mercado e na tecnologia exigem o posicionamento correto das operações na produção de bens e serviços.

Para Sohal e colaboradores (1999), nas últimas décadas as indústrias em muitos países ao redor do mundo foram colocadas sob o microscópio para se examinarem as estratégias e as formas de produção adotadas. O objetivo de muitos desses estudos foi identificar as "melhores" estratégias e práticas que proporcionam um desempenho superior. No entanto, o setor eletroeletrônico brasileiro, apesar de corresponder a 4\% do PIB nacional (Abinee, 2010a), ainda não teve sua gestão de operações analisada profundamente, pois os estudos disponíveis (Gonçalves, 1997; Nassif, 2002; Gutierrez e Alexandre, 2003; CNM e Dieese, 2010; Chami Batista, 2010) focam predominantemente sua trajetória política e macroeconômica.

Em pesquisas realizadas nas mais prestigiosas bases de indexação de artigos científicos brasileiros são encontrados trabalhos que apenas citam o setor eletroeletrônico, mas pouco se sabe como o setor gere suas operações internas e externas (Fensterseifer e Bastos, 1989; Belle, 1991; Slongo, 1996; Martins, 2001; Talamo e Carvalho, 2004; Mafra e Grisci, 2004; Jasen et al., 2005; Araujo e Oliveira, 2006; Hauser et al., 2007; Vianna et al., 2007; Balbinot e Marques, 2009). No entanto, a busca por artigos em bases internacionais permite perceber que há uma discussão mais intensa e detalhada sobre o setor eletroeletrônico em diversos países. Por exemplo, identificação da maturidade da área de pesquisa e desenvolvimento em país em desenvolvimento (Tan e Hwang, 2002), proposta de implementação de sistemas de gestão da produção (Helo, 2004), proposta de modelo de gestão da qualidade (Yeung et al., 2005), intermediação na indústria eletrônica (Shunk et al., 2007) e gestão da cadeia de suprimentos (Singh e Al-Hakim, 2009).

Tendo em vista a lacuna de conhecimento sobre o Brasil no estado da arte sobre o setor eletroeletrônico mundial, este trabalho se propõe a responder "quais são as principais características e tendências do setor eletroeletrônico do Brasil com foco nas operações internas 
(estratégia de produção, forma de atendimento ao pedido do cliente, uso de tecnologia de informação e ações gerenciais) e externas (forma de relacionamento com clientes e fornecedores e adoção de práticas de gestão da cadeia de suprimentos)? O principal objetivo desta pesquisa é traçar o panorama da gestão de operações do setor eletroeletrônico, contribuindo para o meio acadêmico e empresarial, gerando insights sobre oportunidades e desafios e sobre a atuação empresarial e a competição no setor.

\section{Elementos da literatura}

\subsection{Complexo eletroeletrônico do Brasil}

Complexo industrial eletrônico é um conjunto de segmentos e setores industriais caracterizados por uma base técnica similar (a microeletrônica) (Nassif, 2002; Gutierrez e Alexandre, 2003; Hauser et al., 2007). O complexo eletrônico é dividido em quatro segmentos: informática, telecomunicações, automação e bens eletrônicos de consumo (Gonçalves, 1997).

Para Gutierrez e Alexandre (2003), esse complexo possui uma grande importância, pois a eletrônica faz-se presente em quase todas as atividades econômicas (produção de bens de capital, bens de consumo, energia etc.). O estudo de CNMCUT e Dieese (2010) afirma que a qualidade e a magnitude da oferta de produtos elétricos e eletrônicos condicionam as operações e a eficiência de outros segmentos da economia e, por isso, a referida indústria é estratégica para o desenvolvimento nacional.

No Brasil, a trajetória do setor eletroeletrônico passou por diferentes fases desde sua formação até os dias atuais. Conforme Nassif (2002), entre a década de 1950 e a primeira metade da década de 1970, o Brasil não dispunha das empresas que formariam o complexo eletrônico. Nesse período, a indústria eletrônica brasileira era caracterizada pela atividade de empresas produtoras de bens de consumo, cujo capital era, na maior parte dos casos, de origem multinacional.

No início dos anos de 1970 esperava-se uma expressiva expansão da eletrônica de consumo, impulsionada pelos incentivos tributários e fiscais concedidos às empresas que se instalassem na Zona Franca de Manaus (ZFM). A cidade de Manaus situa-se na região Norte do país e fica próxima à floresta Amazônica. A intenção era tornar o Brasil um país exportador de produtos eletrônicos e substituir as importações. Objetivava com a ZFM atrair filiais de empresas multinacionais, mas, em decorrência dessa dinâmica, acarretou a exclusão de diversas empresas de capital nacional do mercado (Nassif, 2002). A falta de competitividade dos bens finais produzidos na ZFM não permitiu a exportação para os grandes mercados, fadando ao fracasso o potencial promissor do mercado produtor interno. Entre as razões para a falta de competitividade, pode-se citar que a região não tinha (e não tem) infraestrutura (má conservação das estradas), mão de obra qualificada e logística de distribuição adequada (distante dos centros de consumos e de produção), o que acarretou custos maiores, mesmo com as isenções fiscais (Chami Batista, 2010). 
Na década de 1980, o país adotou medidas extremas de política industrial com efeitos diretos sobre o setor de produtos eletrônicos. Destacam-se as reservas de mercado no setor de telecomunicações e de microcomputadores, bem como a proibição de importação de uma extensa lista de bens eletrônicos de consumo (Chami Batista, 2010).

No entanto, com a liberalização comercial de 1990, houve um crescimento das importações, fazendo com que a maioria das empresas nacionais se retirasse do mercado; as poucas que permaneceram ficaram em nichos extremamente especializados (Nassif, 2002). Como consequência, a balança comercial do Brasil para o setor eletroeletrônico é até hoje deficitária.

Atualmente, há de incentivo ao setor a Lei no 8.248, conhecida como Lei da Informática, que vigora desde 2001. Ela estabelece que as empresas que aplicarem percentual de sua receita bruta em pesquisa e desenvolvimento na área de informática podem solicitar a redução de imposto (Brasil, 2010a).

Em função da trajetória do setor eletroeletrônico aos longos dos últimos 50 anos, podem-se enumerar algumas de suas características:

v O processo produtivo básico restringe-se à montagem de produtos, a partir de um conjunto total de componentes que são importados; portanto, há uma quase inexistência de produção de componentes eletrônicos. Não há, assim, o ciclo completo de produção de circuitos integrados (componentes que concentram, de forma crescente, as funcionalidades do bem final) (Hauser et al., 2007).

v Os produtos fabricados no Brasil são projetados no exterior e, como consequência, as atividades de engenharia de projetos dos componentes já foram previamente realizadas. Resta ao Brasil adaptar produtos e serviços das multinacionais, customizar e nacionalizá-los para o mercado local (Kronmeyer Filho et al., 2004).

จ O dinamismo do complexo eletrônico prende-se aos sucessivos ciclos de vida de produto, sejam eles radicais ou incrementais, e no Brasil predominam inovações incrementais, relacionadas à funcionalidade e à qualidade do produto (Gonçalves, 1997).

O setor eletroeletrônico corresponde a 4\% do PIB brasileiro de 2009 (Abinee, 2010a). No entanto, em 2009, produtos do complexo eletroeletrônico brasileiro corresponderam a apenas 2,4\% das exportações. Já no total das importações, o setor eletroeletrônico participou com aproximadamente 4,6\% (Brasil, 2010b). Os principais destinos das exportações são América Latina (53\%), Estados Unidos (17\%), União Europeia (12\%) e Sudeste da Ásia (6\%). Entre os principais produtos estão celulares, componentes para equipamentos industriais, motor compressor hermético, eletrônica embarcada e motores e geradores. Quanto às importações, os principais produtos são os semicondutores, componentes para telecomunicações e componentes para informática, vindos principalmente do Sudeste Asiático (61\%), União Europeia (19\%) e Estados Unidos (12,7\%) (CNMCUT e Dieese, 2010).

No Brasil, o setor eletroeletrônico apresenta oportunidades e ameaças, o que requer um melhor conhecimento sobre sua gestão de operações e competitividade. 


\subsection{Aspectos de gestão de operações}

Gestão de operações (ou administração de operações) refere-se ao projeto, direção e controle de processos que transformam insumos em serviços e produtos tanto para clientes internos como externos (Krajewski et al., 2009). Slack e colaboradores (1996) distinguem ao menos cinco grandes grupos de responsabilidades diretas da gestão de operações: (a) entender os objetivos estratégicos da produção, (b) desenvolver uma estratégia de produção para a organização, (c) desenhar produtos, serviços e processos de produção, (d) planejar e controlar a produção e (e) melhorar o desempenho da produção.

As decisões sobre gestão de operações de uma empresa iniciam-se após a definição de uma estratégia empresarial. Em uma perspectiva top down, decisões corporativas são definidas (tipo de indústria, localização etc.) e, a partir daí, definem-se estratégias de negócios (linha de produto, unidade de negócio, mercado-alvo escolhido) e então desmembram-se essas questões em estratégias funcionais (como cada área funcional irá atuar) (Hayes e Wheelwright, 1984). Entre as áreas funcionais, é a estratégia de produção que possui o potencial de alavancar a vantagem competitiva de uma empresa (Skinner, 1969). O conteúdo da estratégia de produção é definido por prioridades competitivas e áreas de decisões (Voss, 1995).

As prioridades competitivas (PC) são definidas como a tradução das necessidades dos clientes, ou seja, os objetivos de desempenho a serem focados pela função produção. Em geral são: qualidade, custos, flexibilidade e entrega (Hayes e Wheelwright, 1984).

Já as áreas de decisões são subdivididas em duas: estruturais (impacto de longo prazo e de elevados investimentos) e infraestruturais (impacto de curto prazo sob pessoas e sistemas). As decisões estruturais versam sobre a natureza da capacidade produtiva (quanto produzir/ como atender ao pedido do cliente), tecnologia empregada (volume e variedade/sistema de produção), tamanho e localização da instalação e grau de integração vertical (produzir internamente, ou terceirizar). As infraestruturais são relativas a recursos humanos (habilidades), gestão da qualidade, planejamento e controle da produção (recursos de programação) e organização (Leong et al., 1990). Portanto, as PC escolhidas na estratégia da empresa afetam a configuração das áreas de decisão e, portanto, iniciam as definições das questões relativas à gestão de operações.

A gestão de operações pode ser interna ou externa à firma. Uma das principais questões sobre operações internas é o planejamento e controle da produção (PCP). O PCP faz parte da decisão infraestrutural e diz respeito à forma como a empresa organiza, aloca e distribui seus recursos de produção (pessoas, máquinas, tempo) para atender aos clientes (volume, mix, prazo etc.).

Atualmente, um conjunto de tecnologias da informação (TI) e ações gerenciais tem sido adotado para informatizar o PCP e a cadeia de suprimentos, como Planejamento de Recursos Empresariais (ERP), o kanban eletrônico (controle de estoque via internet), o Planejamento, Previsão e Reposição Conjunta (CPFR), Estoque Gerenciado pelo Fornecedor (VMI), in plant representative (funcionário de empresa fornecedora presente na empresa cliente). Há algumas 
formas para atender ao pedido do cliente: produzir para estoque (MTS), montar sob pedido (ATO), produzir sob pedido (MTO) e projetar sob pedido (ETO).

Quanto às operações externas, uma questão importante é o grau de desintegração vertical, ou seja, a forma como a organização gerencia sua cadeia de suprimentos (CS). Essa é uma decisão estrutural e implica estabelecer e manter relacionamentos com clientes e fornecedores e implantar práticas de gestão da cadeia de suprimentos (GCS).

GCS é uma abordagem integrativa começando desde o planejamento e controle de materiais, logística, serviços e fluxos de informações até fornecedores, passando por produtores e consumidores finais (Fantazy et al., 2010). Práticas de GCS são definidas como um conjunto de atividades executadas pela organização para promover uma gestão efetiva de sua CS (Li et al., 2005; Li et al., 2006, Koh et al., 2007). Jabbour e colaboradores (2011) consideram práticas de GCS: (a) integração da CS para suporte no PCP, (b) compartilhamento de informações sobre produtos e diretrizes estratégicas, (c) relacionamento estratégico com clientes e fornecedores (d) suporte ao pedido do cliente. Cada categoria tem um conjunto de variáveis que a representam.

O tipo de relacionamento com fornecedores e clientes é um fator determinante da adoção de práticas de GCS. Spekman e colaboradores (1998) estabeleceram alguns tipos de relacionamentos. Em um extremo, as negociações são abertas, sendo as discussões baseadas em preço e no curto prazo. No campo intermediário estão a cooperação e a coordenação com poucos fornecedores, contratos de longo prazo e trocas de informações. Por fim, há a colaboração, com o planejamento conjunto e o compartilhamento de tecnologia entre os fornecedores, com foco no longo prazo.

\section{Metodologia}

\subsection{Objeto de estudo}

As empresas estudadas nesta pesquisa são filiadas à Abinee, que representa os setores elétricos e eletrônicos do Brasil. Fundada em 1963, possui 552 empresas associadas, nacionais e multinacionais.

\subsection{Coleta de dados}

Esta pesquisa é de caráter quantitativo, em que se fez uso de uma survey gerenciada por email, para obtenção de dados.

O instrumento de coleta de dados utilizado foi um questionário com questões fechadas de múltipla escolha, o qual está dividido em quatro seções: a primeira caracteriza o perfil das empresas, a segunda mede o grau de importância das prioridades competitivas da produção, a terceira verifica o grau de implantação de práticas de GCS e identifica o tipo de relaciona- 
mento adotado com os demais elos e a quarta relaciona algumas TI e ações gerenciais que são adotadas nas empresas respondentes.

A seção 1 do questionário tratou de questões como: porte da empresa; identificação da posição da empresa respondente em sua CS principal; poder de barganha na cadeia e forma de atendimento ao pedido do cliente da empresa respondente, por meio de escala nominal.

A seção 2 do questionário, pautada na literatura revisada, teve 13 questões listadas e usou-se uma escala Likert de 5 pontos ( 1 - extremamente irrelevante a 5 - extremamente relevante). A seção 3 adotou as questões validadas por Jabbour e colaboradores (2011) para medir o grau de implantação de práticas de GCS com 22 assertivas sobre práticas de GCS em escala Likert (onde 1 - não implantado e 5 - completamente implantado); os conceitos de Spekman e colaboradores (1998) foram adotados para o entendimento do relacionamento com os demais elos da cadeia Por fim, questionou-se sobre o conjunto de TI e ações gerenciais adotadas nas empresas (Barbosa e Musetti, 2010).

Esta pesquisa adotou como instrumento de coleta de dados o questionário autoadministrável. Aplicou-se pré-teste do questionário autoadministrado antes de seu envio para as unidades de análise. Synodinos (2003) afirma que o teste do questionário é essencial, pois nele identificam-se questões a serem reformuladas. O pré-teste desta pesquisa foi realizado em duas etapas. A primeira com professores da área de gestão de operações e a segunda, com gerentes de empresas.

O questionário foi julgado adequado (em função do feedback dos respondentes e também o cálculo do alfa de Cronbach), dando início à coleta de dados, em quatro etapas. O primeiro passo foi entrar em contato com a área de relações públicas da Abinee para obter a base de dados atualizada de seus filiados. Com o nome e o e-mail do gestor de operações de cada empresa, iniciou-se o segundo passo. Este consistiu em formatar o questionário de uma forma que fosse fácil de acessar e de responder. Utilizaram-se serviços de internet para formular uma página eletrônica com o conteúdo do questionário. A terceira etapa foi enviar e-mails personalizados, a partir do mecanismo de mala direta, para todos os contatos da planilha da Abinee. Foram enviados e-mails para as 552 empresas cadastradas. No entanto, 20 retornaram por questões diversas. A quarta etapa foi gerenciar o retorno dos questionários e fazer eventuais intervenções para aumentar a taxa de retorno.

Depois de transcorridos 44 dias de pesquisa (de julho a meados de setembro de 2009) e três envios de e-mails, a taxa de retorno obtida foi 20\% (107 respondentes), adequada conforme Malhotra e Grover (1998).

\subsection{Análise de dados}

Foram adotadas técnicas de estatística descritiva. As análises descritivas têm como propósito entender a distribuição de frequência de cada variável conforme sua tendência central e de dispersão. Elas são adequadas porque permitem entender quais são os enfoques de competição no setor (prioridade competitiva), as principais práticas de GCS e o uso de TI e ações ge- 
renciais. A análise dos dados teve o suporte do software Statistical Package for Social Science (SPSS). Dados secundários também foram utilizados para complementar as análises (Abinee, 2010b).

\section{Resultados}

\subsection{Caracterização da amostra}

Na amostra, há um predomínio de empresas de pequeno $(31,8 \%)$ e médio $(42,1 \%)$ porte e a participação de 10,3\% de microempresas e de 15,9\% de grandes empresas (figura 1).

\section{Figura 1}

Estratificação por tamanho da amostra da pesquisa

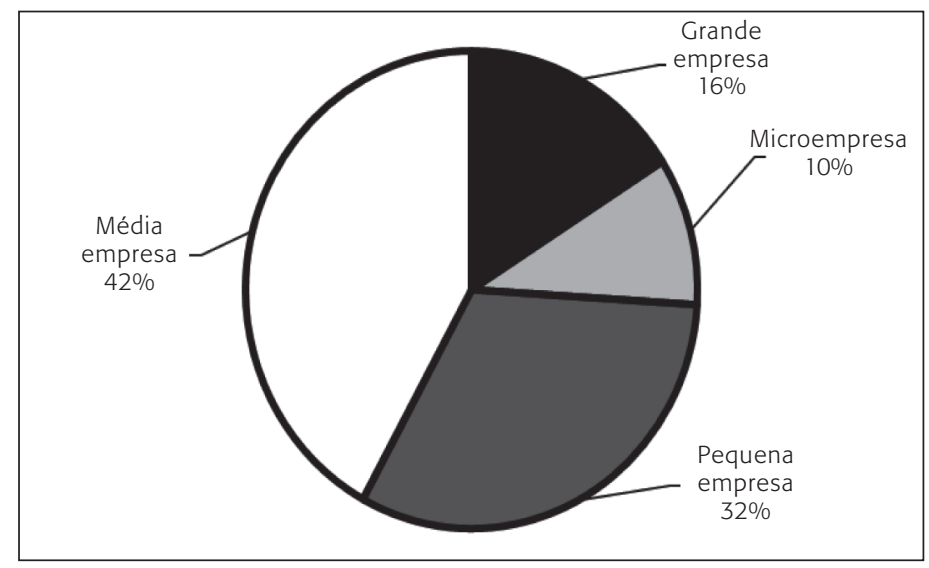

Fonte: Autores.

A posição das empresas em suas CS principais está dividida em: 76,6\% das empresas são montadoras de suas cadeias, $16 \%$ das empresas são fornecedores de componentes, $5 \%$ das empresas são distribuidoras, $2 \%$ são empresas varejistas e $1 \%$ das empresas são fornecedores de matéria-prima básica (figura 2).

A identificação do posicionamento do elo que possui maior poder de barganha na CS principal revela que $81,3 \%$ consideram que seus clientes são as organizações que conseguem coordenar, ou mesmo se impor na cadeia (figura 3). As cadeias do setor eletroeletrônico brasileiro são dirigidas pelos clientes (Kronmeyer Filho et al., 2004). Informação que corrobora o estudo da Abinee (2010b), o qual afirma que o varejo desse setor é muito concentrado, exercendo maior poder de barganha. 
Figura 2

Estratificação da empresa da amostra conforme posição na CS principal

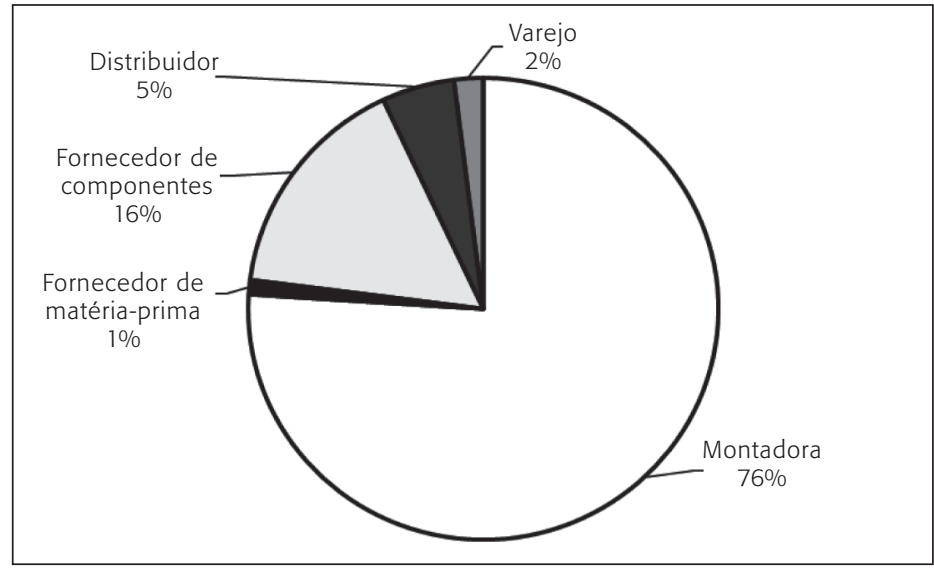

Fonte: Autores.

Figura 3

Distribuição da amostra conforme poder de barganha na CS principal

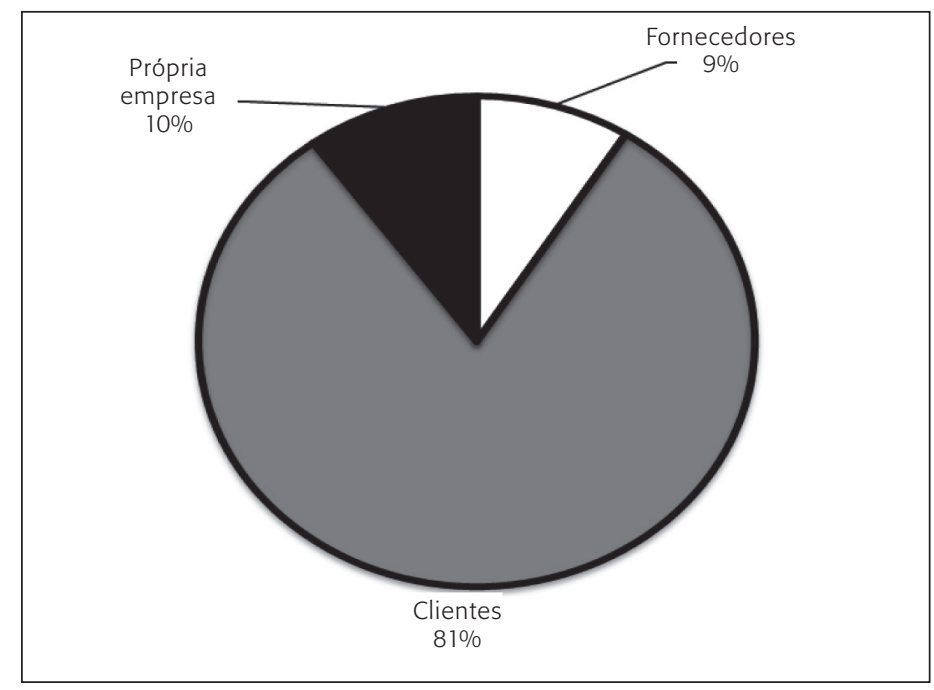

Fonte: Autores.

\subsection{Gestão de operações internas}

De uma forma geral, o conjunto de variáveis relativas às prioridades competitivas foi julgado como relevante a extremamente relevante, o que pode ser visto pelas médias das variáveis 
(tabela 1). A fim de destacar as variáveis mais importantes, e assim indicar uma tendência das PC escolhidas pelas empresas para competirem em seu mercado, usou-se como parâmetro selecionar $25 \%$ das variáveis com maior valor percentual (aludindo à ótica de quartil). Dessa maneira, quatro variáveis indicam a tendência das PC: defeito, requisitos técnicos, data de entrega e funcionalidade, que correspondem aos atributos de "qualidade" e "entrega" das PC mais valorizadas na amostra analisada.

Tabela 1

Tendência geral das PC das empresas estudadas

\begin{tabular}{|c|c|c|c|c|c|c|}
\hline Variáveis & Média & Desvio padrão & $\begin{array}{c}\text { Coeficiente de } \\
\text { variação }\end{array}$ & Máximo & Mínimo & Percentual \\
\hline Prevenir Defeito & 4,86 & 0,375 & 0,077 & 5,00 & 3,00 & 0,97 \\
\hline Seguir Requisito Técnico & 4,74 & 0,572 & 0,12 & 5,00 & 1,00 & 0,95 \\
\hline Atender Data Entrega & 4,70 & 0,499 & 0,106 & 5,00 & 3,00 & 0,94 \\
\hline Funcionalidade & 4,69 & 0,503 & 0,107 & 5,00 & 3,00 & 0,94 \\
\hline Custo Produção & 4,64 & 0,573 & 0,123 & 5,00 & 2,00 & 0,93 \\
\hline Produto Durável & 4,43 & 0,601 & 0,135 & 5,00 & 3,00 & 0,89 \\
\hline Novos Produtos & 4,40 & 0,580 & 0,132 & 5,00 & 3,00 & 0,88 \\
\hline Menor Tempo & 4,31 & 0,605 & 0,140 & 5,00 & 3,00 & 0,86 \\
\hline Volume Produção & 4,32 & 0,667 & 0,154 & 5,00 & 2,00 & 0,86 \\
\hline Mudança Rápida Projeto & 4,09 & 0,734 & 0,179 & 5,00 & 2,00 & 0,82 \\
\hline Menor Preço & 4,00 & 0,752 & 0,188 & 5,00 & 2,00 & 0,80 \\
\hline Gama Produto & 3,86 & 0,745 & 0,193 & 5,00 & 1,00 & 0,77 \\
\hline Variedade Produto & 3,70 & 0,792 & 0,214 & 5,00 & 1,00 & 0,74 \\
\hline
\end{tabular}

O setor eletroeletrônico brasileiro tem como características: importação considerável de componentes estrangeiros, cerca de 30\% das matérias-primas (Abinee, 2010b), competição interna com itens importados e não participação do ciclo completo de produção de seus produtos. Em função dessas características, as empresas brasileiras focam em qualidade, traduzida em redução de defeitos, requisitos técnicos e funcionalidade do produto, pois este setor gera produtos que lidam com uma série de padrões e normas nacionais e internacionais de segurança para serem competitivos internamente e poderem pleitear a exportação. Além do mais, melhorar a funcionalidade do produto é a forma como as empresas brasileiras podem inovar nesse setor (Gonçalves, 1997). Focam também em entrega, pois, como as empresas do setor importam peças de outros países, uma forma de se diferenciar é ter peças em estoque 
para atender de forma confiável os pedidos, uma vez que a logística das importações ocorre, em média, em 90 dias.

As quatro modalidades de atendimento ao cliente são adotadas pelas empresas da amostra. A modalidade produzir sob pedido é a mais utilizada $(33,6 \%)$, seguida pela modalidade montar sob pedido $(27,1 \%)$ e produzir para estoque $(26,2 \%)$. A forma de atendimento menos utilizada é a projetar sob pedido $(13,1 \%)$ (figura 4). Essas respostas podem ser explicadas porque este setor trabalha importando um percentual considerável de peças, tendo de estocá-las para montar os produtos conforme os pedidos e não projetando e produzindo genuinamente produtos novos. O exemplo disso é a forma projetar sob pedido ser a modalidade menos empregada na amostra da pesquisa desse setor, mostrando a fragilidade das empresas na área de desenvolvimento de produtos completamente novos.

Figura 4

Forma de atendimento ao pedido do cliente

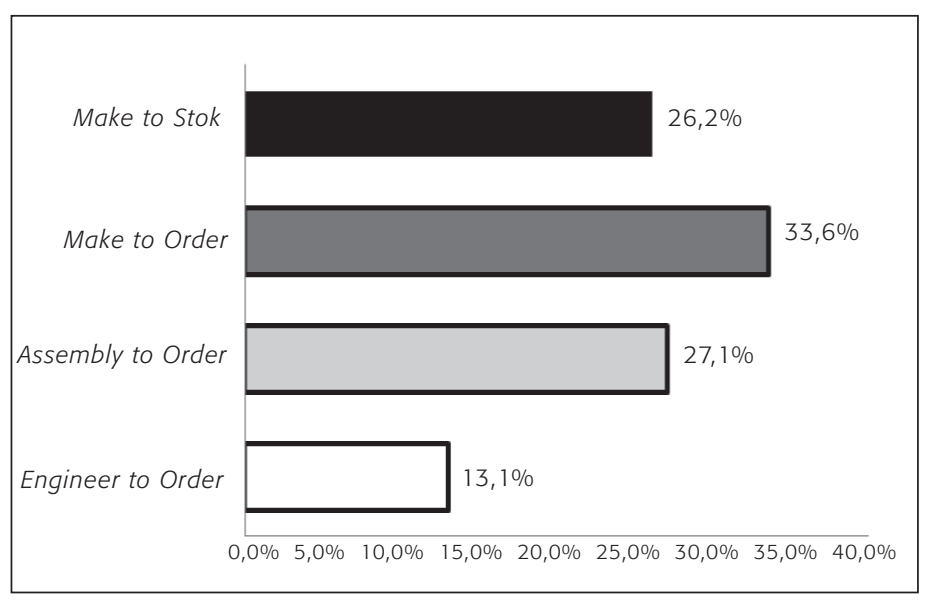

Fonte: Autores.

Diversas TI e ações gerenciais estão sendo empregadas no setor eletroeletrônico para orientar as atividades internas e externas às empresas (figura 5). O ERP é a TI mais adotada entre as empresas pesquisadas (75,7\%); em segundo lugar, tem-se a organização de workshops com clientes (41,1\%); em terceiro lugar, o EDI (Troca Eletrônica de Dados) (31,8\%); e, em quarto lugar, workshop com fornecedores e o uso do kanban eletrônico com 29\%.

Com exceção do ERP, os demais sistemas utilizados visam facilitar o relacionamento entre a empresa, seus clientes e seus fornecedores, e, basicamente, pela troca de informações. Segundo Lankford e Johnson (2000), o EDI é uma forma de comunicação eletrônica que permite a troca de informações e documentos em formatos estruturados, que podem ser processados por determinado tipo de software. São vantagens do EDI (Ferreira e Assumpção, 2005): (a) maior visibilidade para planejamento e controle de estoques (o que apoia a prática do kanban eletrônico), (b) melhor planejamento de entrega de produtos e (c) permite agilidade na transmissão, recebimento, processamento de pedidos e redução de erros. Além 
do EDI, os encontros formais (workshops) realizados entre empresa, clientes e fornecedores ajudam a avaliação do desempenho diante dos clientes, guiando necessidades atuais e futuras sobre produtos e processos operacionais. O ERP contribui internamente com as empresas ao integrar o conjunto de dados dos processos de negócios e, assim, rapidamente gerar relatórios para a tomada de decisão operacional e estratégica, podendo desse modo se planejar adequadamente para obter melhor eficiência operacional.

\section{Figura 5}

Ações adotadas para facilitar a gestão com clientes e fornecedores

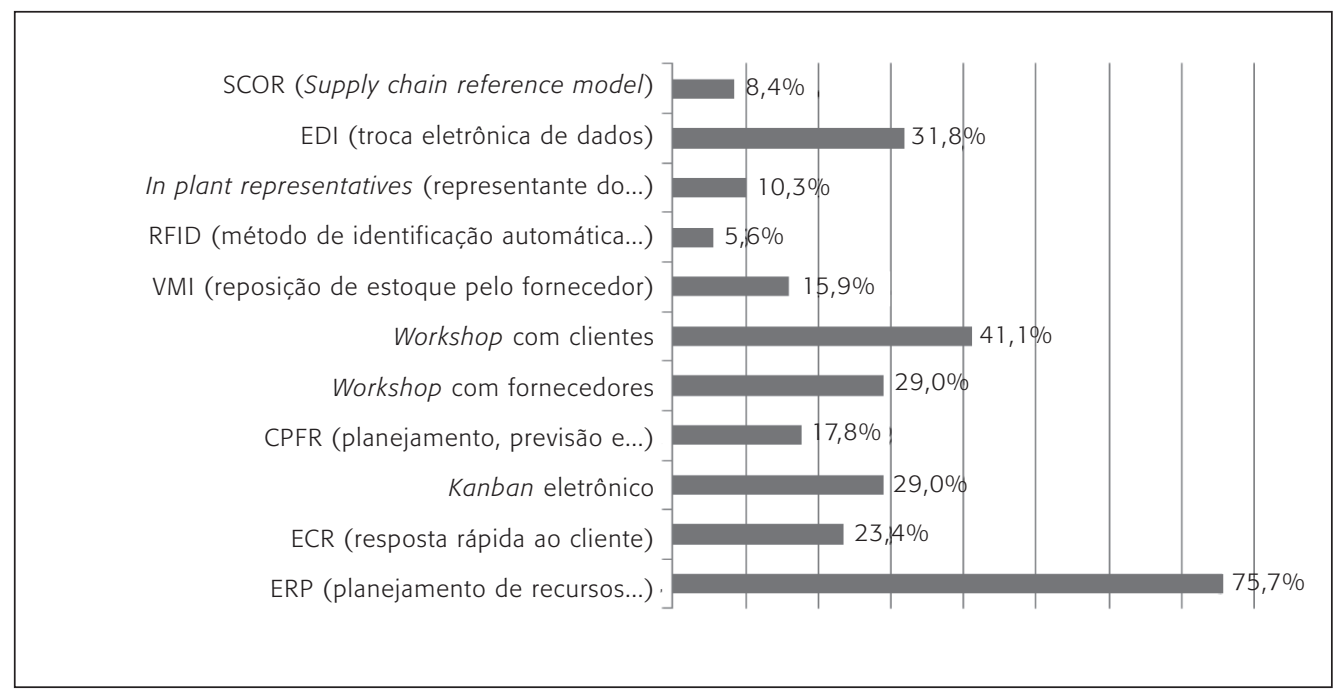

Fonte: Autores.

\subsection{Gestão de operações externas}

Sobre a forma como as empresas do setor eletroeletrônico da amostra se relacionam com seus fornecedores e clientes, pode-se dizer que 55,1\% adotam um relacionamento de longo prazo e com parceria nas atividades de desenvolvimento de produtos com seus fornecedores importantes e estratégicos de componentes (figura 6). Com os outros elos da cadeia não houve uma tendência clara de relacionamentos, pois as respostas foram diversas. Por exemplo, com fornecedores de matéria-prima básica, 38\% das empresas adotam relacionamento de mercado, enquanto 35\% adotam relacionamento de longo prazo (figura 7). A jusante, a tendência não é tão clara, pois com clientes intermediários (distribuidor) a relação ficou dividida entre 35\% que se relacionam na forma de mercado e 35\% que se relacionam na forma de longo prazo (figura 8). Com clientes finais (varejo), 30\% dos respondentes consideram o relacionamento de mercado o mais usual, 30\% dos respondentes consideram o relacionamento de longo prazo e $26 \%$ consideram o relacionamento de longo prazo com parceria nas 
atividades de desenvolvimento de produtos (figura 9). A relação com consumidores finais não é amplamente trabalhada (figura 10).

Figura 6

Relacionamento da empresa com fornecedores importantes e estratégicos de componentes

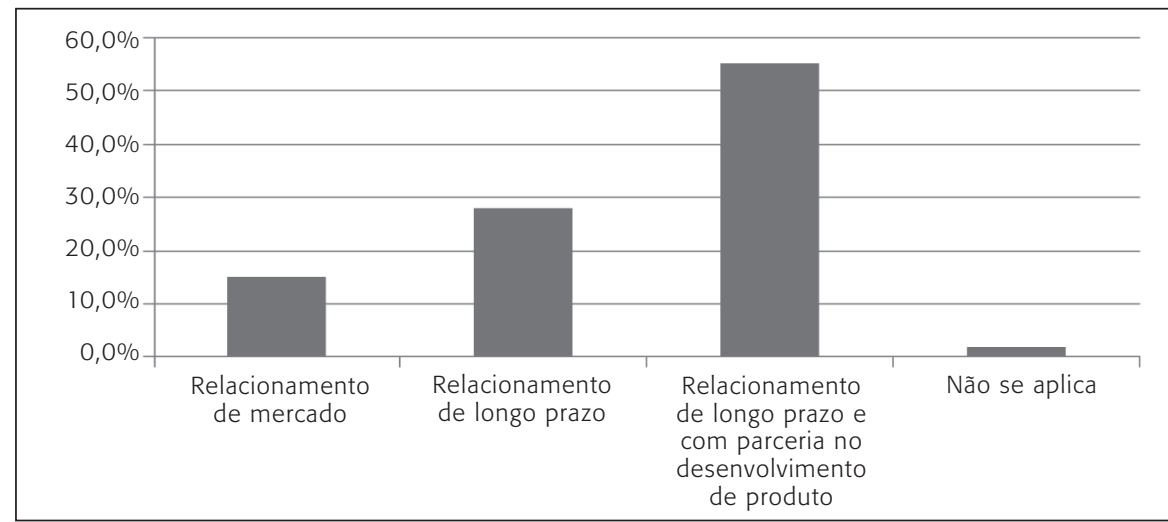

Fonte: Autores.

Figura 7

Relacionamento da empresa com fornecedores de matéria-prima básica

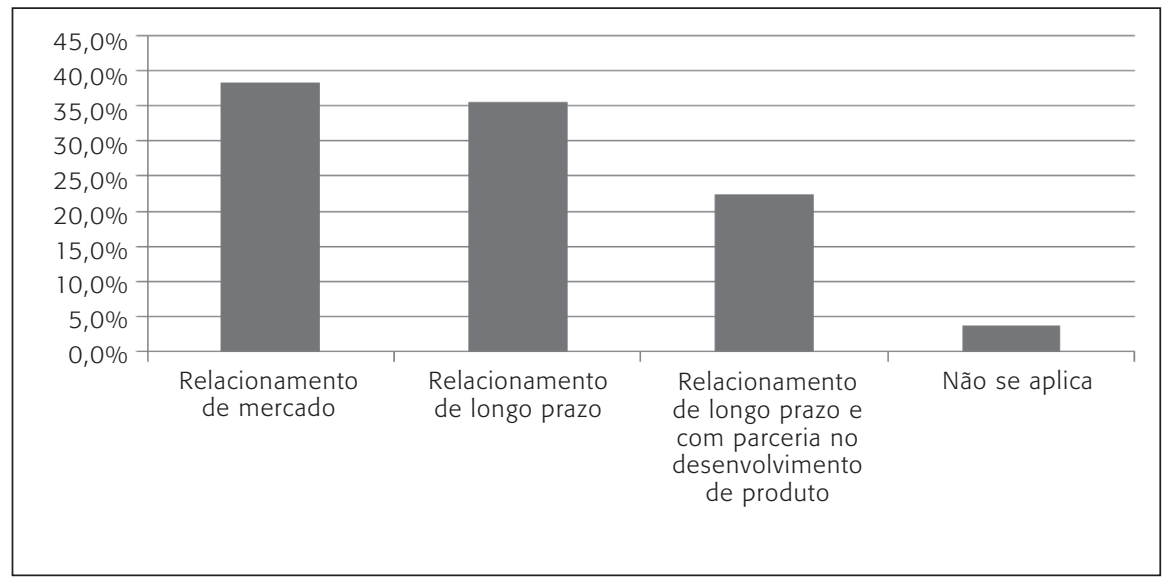

Fonte: Autores. 
Figura 8

Relacionamento da empresa com clientes intermediários

(distribuidor/atacadista)

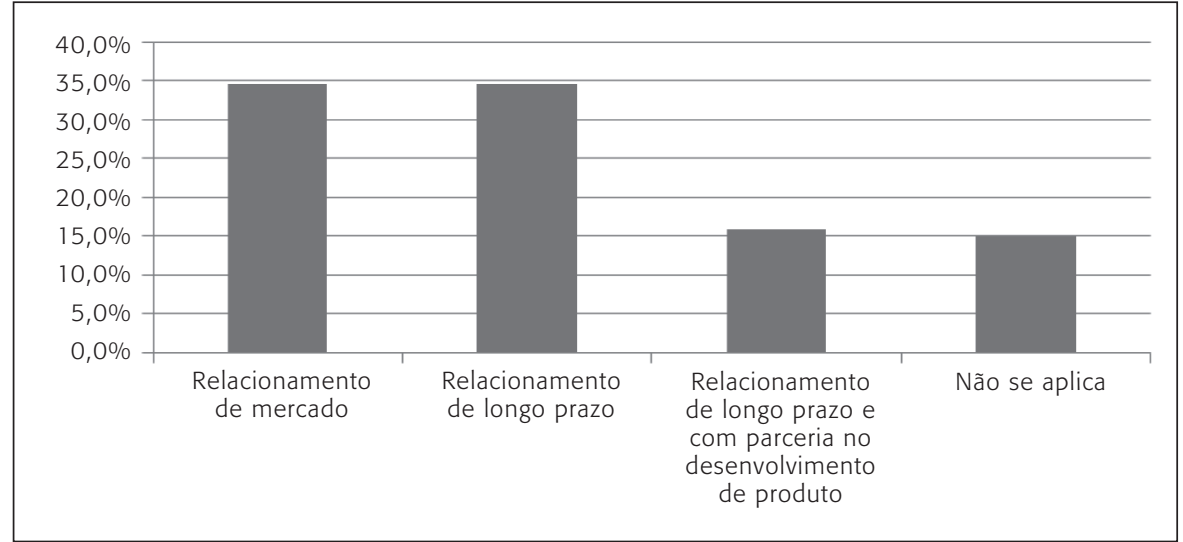

Fonte: Autores.

Figura 9

Relacionamento da empresa com clientes finais (varejo)

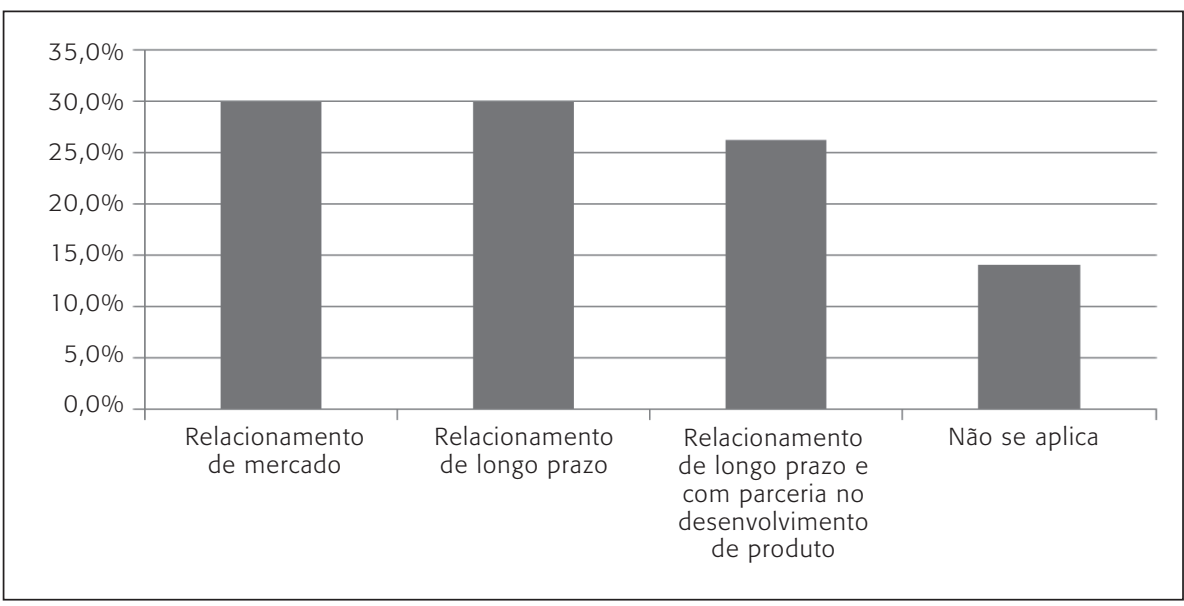

Fonte: Autores. 
Figura 10

Relacionamento da empresa com consumidor final (pessoa física)

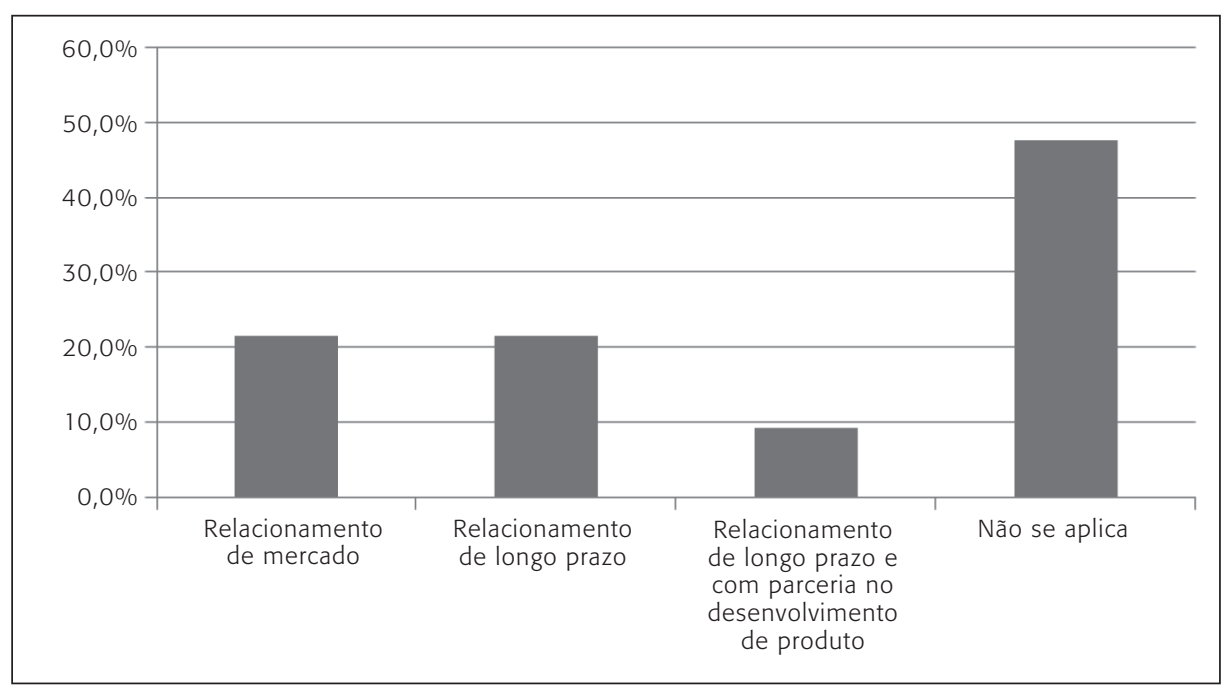

Fonte: Autores.

Os relacionamentos mais prósperos entre as empresas estudadas são com seus fornecedores importantes e estratégicos de componentes (1aㅡ camada) e com o varejo (clientes de $2^{\mathrm{a}}$ camada).

Com os fornecedores de componentes, o relacionamento predominante é o de longo prazo e com parceria em atividades de desenvolvimento de produto, que pode ser explicado pelos argumentos de: (a) quanto mais sofisticado tecnologicamente o produto, mais estratégico o relacionamento deve ser, resultando na redução da base de fornecedores (Berry, Towill e Wadsley, 1994); e (b) empresas montadoras de produtos eletrônicos constantemente reprojetam seus produtos com o objetivo de reduzir custos e aumentar a funcionalidade, tendo muita ênfase no apoio dos fornecedores nesse processo (McIvor e Humphreys, 2004).

Quanto ao relacionamento com os clientes varejistas, é predominantemente de longo prazo e com tendência ao apoio nas atividades de desenvolvimento de produto. Pode ser explicado pelo fato de a jusante da cadeia ser o elo forte da maioria das montadoras estudadas. Ou seja, são essas empresas que exercem influência no restante da cadeia (Mouritsen et al., 2003), sendo importante a sintonia nas operações e no relacionamento, pois a empresa mais próxima aos consumidores recebe informações mais claras e mais rápidas sobre demanda e estoque, ou seja, manter um relacionamento de longo prazo apoia a eficiência interna das operações das montadoras (Berry, Towill e Wadsley, 1994).

A tabela 2 mostra o panorama quanto à adoção das práticas de GCS. 
Tabela 2

Tendência central e de dispersão da adoção de práticas de GCS

\begin{tabular}{|c|c|c|c|c|c|}
\hline Variável & Média & $\begin{array}{l}\text { Desvio } \\
\text { padrão }\end{array}$ & $\begin{array}{l}\text { Coeficiente de } \\
\text { variância }\end{array}$ & Mediana & Percentual \\
\hline Feedback Cliente & 3.77 & 1.112 & 0.294 & 4 & 0.75 \\
\hline $\begin{array}{l}\text { Necessidades Futuras } \\
\text { Clientes }\end{array}$ & 3.30 & 1.191 & 0.361 & 4 & 0.66 \\
\hline Integração Fornecedor & 3.32 & 1.364 & 0.411 & 4 & 0.66 \\
\hline $\begin{array}{l}\text { Colaboração Fornecedor } \\
\text { Previsão Demanda }\end{array}$ & 3.24 & 1.338 & 0.413 & 4 & 0.65 \\
\hline $\begin{array}{l}\text { Apoio Cliente Novo } \\
\text { Produto }\end{array}$ & 3.27 & 1.263 & 0.386 & 4 & 0.65 \\
\hline Integração Cliente & 3.15 & 1.309 & 0.415 & 3 & 0.63 \\
\hline $\begin{array}{l}\text { Colaboração Fornecedor } \\
\text { Planejamento Produção }\end{array}$ & 3.09 & 1.438 & 0.465 & 3 & 0.62 \\
\hline $\begin{array}{l}\text { Colaboração Cliente } \\
\text { Previsão Demanda }\end{array}$ & 3.09 & 1.285 & 0.416 & 3 & 0.62 \\
\hline $\begin{array}{l}\text { Colaboração Fornecedor } \\
\text { Planejamento Estoque }\end{array}$ & 3.07 & 1.445 & 0.470 & 3 & 0.61 \\
\hline $\begin{array}{l}\text { Colaboração Cliente } \\
\text { Planejamento Estoque }\end{array}$ & 3.03 & 1.397 & 0.461 & 3 & 0.61 \\
\hline $\begin{array}{l}\text { Apoio Fornecedor } \\
\text { Desenvolvimento Produto }\end{array}$ & 3.07 & 1.406 & 0.457 & 4 & 0.61 \\
\hline $\begin{array}{l}\text { Colaboração Cliente } \\
\text { Planejamento Produção }\end{array}$ & 2.97 & 1.404 & 0.473 & 3 & 0.59 \\
\hline $\begin{array}{l}\text { Consulta Fornecedor } \\
\text { Programação Produção }\end{array}$ & 2.92 & 1.487 & 0.510 & 3 & 0.58 \\
\hline $\begin{array}{l}\text { Consulta Cliente } \\
\text { Programação Produção }\end{array}$ & 2.87 & 1.530 & 0.533 & 3 & 0.57 \\
\hline $\begin{array}{l}\text { Envolvimento Fornecedor } \\
\text { Planos }\end{array}$ & 2.79 & 1.419 & 0.508 & 3 & 0.56 \\
\hline $\begin{array}{l}\text { Envolvimento Cliente } \\
\text { Planos }\end{array}$ & 2.79 & 1.358 & 0.486 & 3 & 0.56 \\
\hline $\begin{array}{l}\text { Comunicação Estratégia } \\
\text { Futura Fornecedor }\end{array}$ & 2.64 & 1.369 & 0.518 & 3 & 0.53 \\
\hline $\begin{array}{l}\text { Informação Fornecedor } \\
\text { Lançamento Produto }\end{array}$ & 2.61 & 1.323 & 0.506 & 3 & 0.52 \\
\hline $\begin{array}{l}\text { Participação Marketing } \\
\text { Cliente }\end{array}$ & 2.53 & 1.383 & 0.546 & 3 & 0.51 \\
\hline Montagem Próxima Cliente & 2.38 & 1.527 & 0.641 & 2 & 0.48 \\
\hline $\begin{array}{l}\text { Compartilhamento } \\
\text { Informação Custo Cliente }\end{array}$ & 2.12 & 1.385 & 0.653 & 1 & 0.42 \\
\hline $\begin{array}{l}\text { Criação Equipes } \\
\text { Multifuncionais }\end{array}$ & 2.05 & 1.334 & 0.650 & 1 & 0.41 \\
\hline Média & & & & 3.05 & \\
\hline
\end{tabular}

Fonte: Autores. 
Os resultados indicam que o estágio atual de adoção de práticas de GCS encontra-se em média na fase "parcialmente implantada", uma vez que a média das medianas foi de 3,05 (valor que corresponde a "parcialmente implantado", conforme a escala Likert).

Têm-se seis variáveis que podem ser destacadas:

v "Obtenção de feedback dos clientes finais sobre a adequação do produto";

v "Determinação das necessidades futuras do cliente";

v "Integração das atividades de desenvolvimento de produto com os fornecedores";

v "Colaboração dos fornecedores na previsão de demanda";

v "Consulta aos clientes para apoiar a decisão de novos produtos";

v "Integração das atividades de desenvolvimento de produtos com os clientes".

Há um maior número de práticas direcionadas aos clientes. Isso pode ser uma evidência da influência do elo forte da cadeia, ou seja, os clientes exercem um poder sobre as empresas mais a montante, o que eventualmente implica maiores esforços de relacionamento e suporte aos clientes (Mouritsen et al., 2003).

A figura 11 sintetiza os principais resultados da pesquisa, quanto à gestão de operações das empresas do setor eletroeletrônico brasileiro.

Figura 11

Síntese dos principais resultados quanto à gestão de operações do setor eletroeletrônico brasileiro

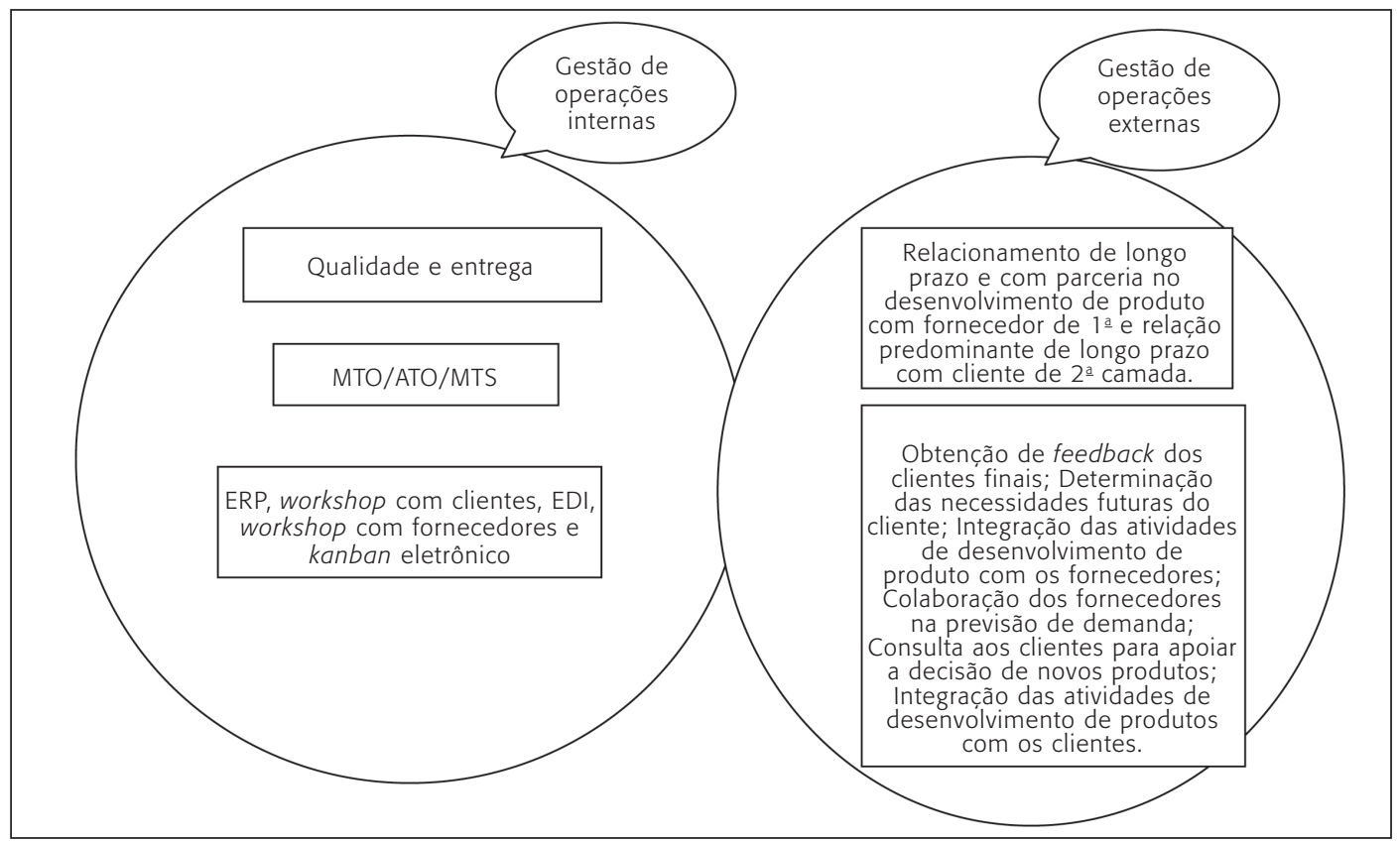

Fonte: Autores. 


\subsection{Discussões}

Algumas constatações podem ser realizadas quanto à gestão de operações internas. As empresas brasileiras não competem por custos (menor preço) e sim por qualidade e entrega. Isso pode ser uma alternativa para lidar com a concorrência de produtos mais baratos vindos principalmente da Ásia (que competem por custo) e com a interferência da taxa cambial na formação dos preços dos produtos finais.

As formas de atendimento aos pedidos do cliente mais adotadas (montar sob pedido e produzir para estoque) estão alinhadas às prioridades competitivas, principalmente entrega. Seja finalizando a montagem do produto após o recebimento do pedido, ou atendendo ao pedido do cliente a partir de produtos em estoque, o lead time de atendimento ao pedido do cliente é mais reduzido e confere confiabilidade à entrega.

Há evidências de alinhamento entre TI, prioridades competitivas e as formas de atendimento ao cliente das empresas do setor eletroeletrônico. Algumas TI se destinam ao controle de estoque (EDI e kanban eletrônico) e consequentemente promovem a confiabilidade de entrega; outras (workshops com clientes e fornecedores) intencionam a busca da qualidade dos produtos a partir da interação com clientes e fornecedores quanto a necessidades futuras e feedback do cliente.

Já o alinhamento entre práticas adotadas e estratégias parece menos intenso. Por exemplo, o elo forte da cadeia eletroeletrônica são os clientes de $2^{\text {a }}$ camada, com quem as montadoras mantêm relacionamento predominantemente de longo prazo com parceria em desenvolvimentos de produtos, implementando um conjunto de práticas de GCS relevantes para a qualidade do produto (feedback do cliente e determinação das necessidades futuras dos clientes) e o desenvolvimento de produto. Entretanto, as montadoras adotam poucas TI e ações gerenciais, destacando-se apenas EDI e workshops. Dessa forma, as práticas de GCS parecem não estar sendo apoiadas pelas TI, o que pode indicar que as práticas de GCS podem ser pouco efetivas na prática.

Outra aparente inconsistência acorre a montante da cadeia de suprimentos das mon-

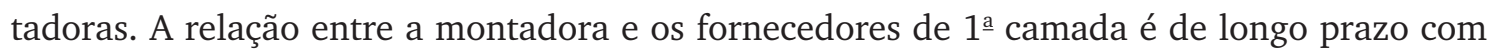
parcerias em desenvolvimento de produtos, tendo o suporte de TI e ações gerenciais (EDI, kanban eletrônico e workshop); no entanto, há potencial de se implantar mais práticas de GCS, a fim de estabelecer um relacionamento mais efetivo com os fornecedores, alavancando a competitividade com base na qualidade (funcionalidade de produto) e entrega, principalmente porque a maior parte das empresas está geograficamente próxima (70\% das matériasprimas são de origem nacional). A figura 12 ilustra as relações entre os elos da CS do setor eletroeletrônico brasileiro. 
Figura 12

Relações entre elos da CS do setor eletroeletrônico brasileiro

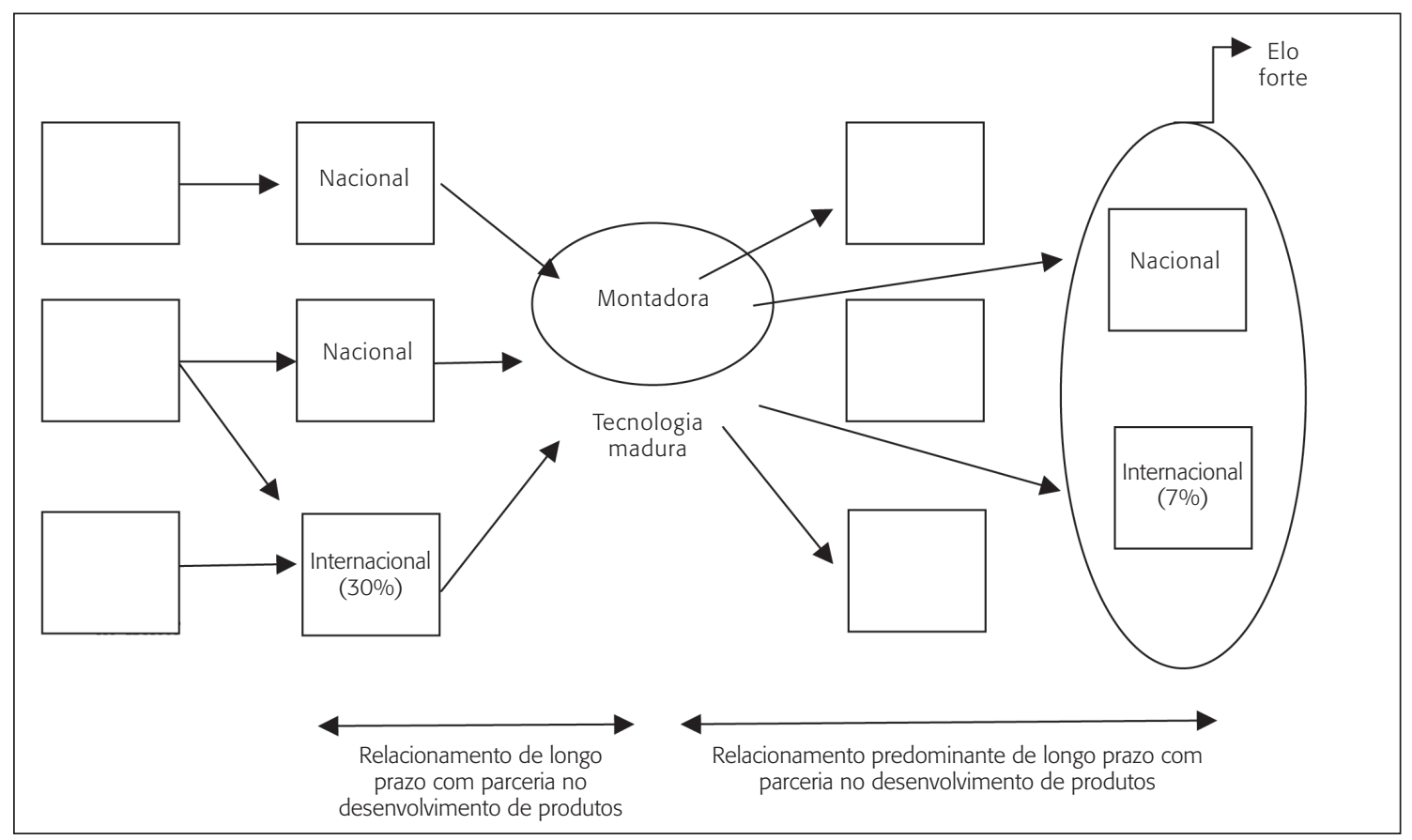

Fonte: Autores.

\section{Conclusões}

Este artigo caracterizou a gestão de operações interna e externa de empresas do setor eletroeletrônico no Brasil, ponto de vista até então pouco utilizado para a compreensão do setor.

Os principais resultados da pesquisa são: (a) no setor predominam empresas nacionais de pequeno e médio porte, (b) as empresas competem com foco em qualidade de produto e confiabilidade de entrega, (c) os varejistas são o elo que possui maior poder de barganha na cadeia eletroeletrônica, (d) as empresas montadoras do setor mantêm relacionamentos de longo prazo e com parcerias em desenvolvimento de produtos com seus fornecedores de $1^{\text {a }}$ camada, enquanto com seus clientes de $2^{\text {a }}$ camada é predominantemente de longo prazo e com tendência a parceria no desenvolvimento de produtos, (e) as empresas do setor adotam tecnologias de informações e ações gerenciais (ERP, EDI, workshops e kanban eletrônico) para apoiar sua gestão interna e externa e (f) as práticas de gestão da cadeia de suprimentos mais adotadas são voltadas aos clientes, como obtenção do feedback do cliente, determinação das necessidades futuras desses, consulta aos clientes para apoiar a decisão de novos produtos e integração das atividades de desenvolvimento de produtos com os clientes.

A partir das análises realizadas, constata-se que a gestão de operações internas apresenta significativo alinhamento entre a forma de competir, a forma de atender ao pedido do cliente e o uso de TI e ações gerenciais. No entanto, há evidências de pouco alinhamento 
entre práticas e estratégias da gestão de operações externas. As montadoras adotam práticas de GCS com os clientes (elo forte da cadeia), mas parecem não usar de forma significativa TI, comprometendo a efetividade das práticas de GCS que são intensivas em TI.

Em relação à gestão de operações a montante, a relação mantida entre as montadoras e os fornecedores favorece o uso de TI e ações gerenciais; no entanto, constatou-se que não há adoção representativa de práticas de GCS. Assim, há oportunidades para montadoras investirem no uso mais intenso de TI com os clientes, além de ampliarem a adoção de mais práticas de GCS com seus fornecedores.

O setor eletroeletrônico passou por diferentes fases ao longo de seu processo de desenvolvimento no Brasil. Houve a intervenção governamental em diferentes momentos na intenção de alavancar o setor, mas, no entanto, estas políticas não foram bem-sucedidas. A consequência é uma tendência de pouca competitividade do setor em função da inexistência do ciclo completo de produção, causando a dependência por componentes e produtos importados, e dependência das multinacionais que atuam no país. Para superar anos de defasagem tecnológica e atrasos acarretados é necessário investir na eficiência da gestão de operações. É necessário que empresas montadoras invistam mais em TI para ampliar a integração de processos, planejamento da produção e desenvolvimento de produto entre essas e seus clientes e ampliar a adoção de práticas de GCS com as empresas fornecedoras. Cabe então às empresas brasileiras apostarem na eficiência da gestão de operações para superar os pontos negativos da história do setor.

Sugere-se, também, que sejam criadas políticas direcionadas à produção interna de componentes de circuito integrado, para estimular a cadeia produtiva brasileira. O poder público poderia tomar a lição da Zona Franca de Manaus como exemplo, para não cometer os mesmos erros e incentivar outras regiões do país, como a Centro-Oeste ou Nordeste, regiões ainda pouco desenvolvidas para a instalação de polos produtivos de componentes eletroeletrônicos. É importante que o desenvolvimento do setor eletroeletrônico ocorra com um planejamento de infraestrutura logística para escoamento da produção (rodovias, ferrovias, portos etc.) e de universidades que formem recursos humanos capacitados. Um polo industrial mais forte nessas regiões atrairia investimentos privados, gerando emprego e renda, reduzindo o desequilíbrio entre regiões brasileiras.

Este artigo apresenta limitações, como o foco na realidade de um único setor industrial do Brasil, que, no entanto, pode trazer lições para outros países em condições semelhantes, a fim de lançar luzes à importância tanto do poder público como, principalmente, do gerenciamento efetivo das operações internas e externas. Espera-se que pesquisas futuras utilizem as informações aqui contidas para comparar a realidade do setor eletroeletrônico brasileiro com dados de outros países do mundo.

\section{Referências}

ABINEE. Associação Brasileira da Indústria Nacional de Elétrica Eletrônica. 2010a. Disponível em: <www.abinee.org.br>. Acesso em: 17 nov. 2011. 
ABINEE. Consolidação da pesquisa com as pequenas e médias empresas do setor eletroeletrônico. 2010b. Disponível em: <www.abinee.org.br/informac/arquivos/pan2010.pdf>. Acesso em: 23 nov. 2010.

ARAUJO, A.M.C.; OLIVEIRA, E.M. Reestruturação produtiva e saúde no setor metalúrgico: a percepção das trabalhadoras. Sociedade e Estado, v. 21, n. 1, p. 169-198, 2006.

BALBINOT, Z.; MARQUES, R.A. Alianças estratégicas como condicionantes do desenvolvimento da capacidade tecnológica: o caso de cinco empresas do setor eletroeletrônico brasileiro. Revista de Administração Contemporânea, v. 13, n. 4, p. 604-625, 2009.

BARBOSA, D.B.; MUSETTI, M.A. Logistics information systems adoption: an empirical investigation in Brazil. Industrial Management \& Data Systems, v. 110, n. 6, p. 787-804, 2010.

BELLE, F. Cultura de empresa e identidades profissionais. Revista de Administração da USP, v. 26, n. 2, p. 40-59, 1991.

BERRY, D.; TOWILL, D.R.; WADSLEY, N. Supply chain management in the electronics products industry. International Journal of Physical Distribution \& Logistics Management, v. 24, n. 10, p. 20 32, 1994.

BRASIL. Ministério do Desenvolvimento, Indústria e Comércio Exterior. 2010a. Disponível em: $<$ www.mdic.gov.br//sitio/interna/interna.php?area $=2 \&$ menu=1103 > . Acesso em: 23 nov. 2010.

BRASIL. Ministério do Desenvolvimento, Indústria e Comércio Exterior. 2010b. Disponível em: <www.mdic.gov.br//arquivos/dwnl_1271956409.pdf>. Acesso em: 10 nov. 2010.

CHAMI BATISTA, J. Os efeitos das políticas industriais para o setor de produtos eletrônicos do Brasil. Revista de Economia Política, v. 30, n. 1, p. 112-123, 2010.

CNM/CUT (CONFEDERAÇÃO NACIONAL DOS METALÚRGICOS); DIEESE (DEPARTAMENTO INTERSINDICAL DE ESTATÍSTICA E ESTUDOS SOCIOECONÔMICOS). Setor eletroeletrônico no Brasil: texto de apoio com informações gerais. 2010. Disponível em: <www.imfmetal.org/files/10041915024410005/Dorival_Jesus_do_Nacimento.pdf>. Acesso em: 21 nov. 2010.

FANTAZY, K.A. et al. Supply management practices and performance in the Canadian hospitality industry. International Journal of Hospitality Management, v. 29, n. 4, p. 685-693, 2010.

FENSTERSEIFER, J.E.; BASTOS, R.M. A implantação de sistemas MRP de gestão da produção e de materiais nas grandes empresas industriais do Brasil. Revista de Administração da USP, v. 24, n. 1, p. 11-22, 1989.

FERREIRA, K.A.; ASSUMPÇÃO, M.R.P. Logística e troca de informações em empresas automobilísticas e alimentícias. Revista Produção, v. 15, n. 3, p. 434-447, 2005.

FLEURY, A. The changing pattern of operations management in developing country: the case of Brazil. International Journal of Operations \& Production Management, v. 19, n. 5/6, p. 552-564, 1999.

FLEURY, A.; FLEURY, M.T. The evolution of production systems and conceptual frameworks. Journal of Manufacturing Technology Management, v. 18, n. 8, p. 949-965, 2007. 
GONÇALVES, R.R. O setor de bens de eletrônicos de consumo no Brasil: uma análise de seu desempenho recente e perspectivas de evolução futura. Texto para Discussão, n. 476, 1997. Disponível em: <http://www.ipea.gov.br/pub/td/td0476.pdf>. Acesso em: 13 dez. 2010.

GUTIERREZ, R.M.V.; ALEXANDRE, P.V.M. Complexo eletrônico brasileiro e competitividade. BNDES Setorial, n. 18, p. 165-192, 2003. Disponível em: <www.bndes.gov.br/SiteBNDES/export/sites/default/bndes_pt/Galerias/Arquivos/conhecimento/bnset/set1805.pdf >. Acesso em: 13 dez. 2010.

HAUSER, G. et al. A indústria eletroeletrônica no Brasil e na China: um estudo comparativo e a análise das políticas públicas de estímulo a capacidade tecnológica do setor. Journal of Technology Management \& Innovation, v. 2, n. 3, p. 85-96, 2007.

HAYES, R.H.; WHEELWRIGHT, S.C. Restoring our competitive edge: competing through manufacturing. New York: John Wiley \& Sons, 1984.

HELO, P. Managing agility and productivity in the electronics industry. Industrial Management \& Data Systems, v. 104, n. 7, p. 567-577, 2004.

JABBOUR, A.B.L.S. et al. Measuring supply chain management practices. Measuring Business Excellence, v. 15, n. 2, 2011.

JASEN, L.K.C. et al. Estratégias de sobrevivência para pequenas e médias empresas em ambientes globalizados: um estudo de caso do setor eletroeletrônico. Gestão \& Produção, v. 12, n. 3, p. 405416, 2005.

$\mathrm{KOH}$, S.S. et al. The impact of supply chain management practices on performance of SMES. Industrial Management \& Data Systems, v. 107, n. 1, p. 103-124, 2007.

KRAJEWSKI, L. et al. Administração de produção e operações. São Paulo: Pearson Prentice Hall, 2009.

KRONMEYER FILHO, O.R. et al. O mapeamento da cadeia eletrônica no RS: um estudo inicial. In: ENCONTRO NACIONAL DE ENGENHARIA DE PRODUÇÃO (ENEGEP), XXIV, Florianópolis, 2004. Anais... Rio de Janeiro: Abepro, 2004. p. 3648-3655.

LANKFORD, W.M.; JOHNSON, J.E. EDI via the internet. Information Management \& Computer Security, v. 8, n. 1, p. 27-30, 2000.

LEONG, G.K. et al. Research in the process and content of manufacturing strategy. Omega, v. 18, n. 2, p. 109-122, 1990.

LI, S. et al. The impact of supply chain management practices on competitive advantage and organizational performance. Omega, v. 34, p. 107-124, 2006.

LI, S. et al. Development and validation of a measurement instrument for studying supply chain management practices, Journal of Operations Management, v. 23, p. 618-641, 2005.

MAFRA, R.; GRISCI, C.L.I. Reestruturação produtiva e modos de gestão de pessoas em uma empresa do setor eletroeletrônico de Santa Catarina. Revista Eletrônica de Administração, v. 10, n. 3, p. 1-24, 2004. 
MALHOTRA, M.K.; GROVER, V. An assessment of survey research in POM: from constructs to theory. Journal of Operations Management, v. 16, n. 4, p. 407-425, 1998.

MARTINS, H.H.TS. O processo de reestruturação produtiva e o jovem trabalhador: conhecimento e participação. Tempo Social, v. 13, n. 2, p. 61-87, 2001.

MCIVOR, R.; HUMPHREYS, P. Early supplier involvement in the design process: lessons from the electronics industry. Omega, v. 32, p. 179-199, 2004.

MOURITSEN, J. et al. Exploring the contours of supply chain management. Integrated Manufacturing Systems, v. 14, n. 8, p. 686-695, 2003.

NASSIF, A. Complexo eletrônico brasileiro. BNDES 50 anos: histórias setoriais. 2002. Disponível em: <www.bndespar.com.br>. Acesso em: 17 out. 2009.

PRENTIS, E.L. Operations management taxonomy. Journal of Operations Management, v. 7, n. 1/2, p. 63-78, 1987.

SHUNK, D.L. et al. Electronics industry drivers of intermediation and disintermediation. International Journal of Physical Distribution \& Logistics Management, v. 37, n. 2, p. 248-261, 2007.

SINGH, S.; AL-HAKIM, L. Managing supply chain at high technology companies. IEE Computer Society, v. 83, p. 400-409, 2009.

SKINNER, W. Manufacturing-missing link in corporate strategy. Harvard Business Review, p. 136145, May/June 1969.

SLACK, N. et al. Administração da produção. São Paulo: Atlas, 1996.

SLONGO, L.A. Serviços ao cliente na indústria eletroeletrônica no Rio Grande do Sul. Revista de Administração da USP, v. 31, n. 4, p. 57-76, 1996.

SOHAL, A.S. et al. Manufacturing practices and competitive capability: an Australian study. Technovation, v. 19, p. 295-304, 1999.

SPEKMAN, R.E. et al. An empirical investigation into supply chain management - a perspective on partnerships. International Journal of Physical Distribution \& Logistics Management, v. 28, n. 8, p. 630-650, 1998.

SYNODINOS, N. E. The "art" of questionnaire construction: some important considerations for manufacturing studies. Integrated Manufacturing Systems, v. 14, n. 3, p. 221-237, 2003.

TALAMO, J.R.; CARVALHO, M.M. Seleção dos objetivos fundamentais de uma rede de cooperação empresarial. Gestão \& Produção, v. 11, n. 2, p. 239-250, 2004.

TAN, L.; HWANG, A.R. Imported technology and R\&D in the Taiwanese electronic industry. Review of Development Economics, v. 6, n. 1, p. 77-90, 2002.

VIANNA, N.W.H. et al. Indústria eletroeletrônica brasileira: estratégias de entrada e desafios do processo de internacionalização. Revista Eletrônica de Administração, v. 13, n. 4, p. 1-22, 2007. 
VOSS, C.A. Alternative paradigms for manufacturing strategy. International Journal of Operations \& Production Management, v. 15, n. 4, p. 5-16, 1995.

YEUNG, A.C.L. et al. An empirical model for managing quality in the electronics industry. Production and Operations Management, v. 14, n. 2, p. 189-204, 2005.

Ana Beatriz Lopes de Sousa Jabbour é professora assistente doutora no Departamento de Engenharia de Produção da Faculdade de Engenharia de Bauru (FEB), da Universidade Estadual Paulista (Unesp). E-mails: abjabbour@feb.unesp.br, ablsjabbour@gmail.com.

Charbel José Chiappetta Jabbour é professor assistente doutor no departamento de Engenharia de Produção da FEB, da Unesp. E-mail: prof.charbel@gmail.com. 